\title{
A history of the concept of time of concentration
}

\author{
Keith J. Beven \\ Lancaster Environment Centre, Lancaster University, Lancaster, UK \\ Correspondence: Keith J. Beven (k.beven@ lancaster.ac.uk) \\ Received: 1 November 2019 - Discussion started: 16 January 2020 \\ Revised: 2 April 2020 - Accepted: 21 April 2020 - Published: 25 May 2020
}

\begin{abstract}
The concept of time of concentration in the analysis of catchment responses dates back over 150 years to the introduction of the rational method. Since then it has been used in a variety of ways in the formulation of both unit hydrograph and distributed catchment models. It is normally discussed in terms of the velocity of flow of a water particle from the furthest part of a catchment to the outlet. This is also the basis for the definition in the International Glossary of Hydrology. While conceptually simple, this definition is, however, wrong when applied to catchment responses where, in terms of how surface and subsurface flows produce hydrographs, it is more correct to discuss and teach the concept based on celerities and time to equilibrium. While this has been recognized since the 1960s, some recent papers and texts remain confused over the definition and use of the time of concentration concept. The paper sets out the history of its use and clarifies its relationship with time to equilibrium but suggests that both terms are not really useful in explaining hydrological responses. An Appendix is included that quantifies the differences between the definitions of response times for subsurface and surface flows under simple assumptions that might be useful in teaching.
\end{abstract}

\section{Introduction}

The concept of the time of concentration of a catchment dates back to at least Mulvany (1851, reproduced in Loague, 2010) as the basis for estimating an appropriate timescale for rainfall duration in the rational method for estimating peak flows. More recently, time of concentration was defined by the International Glossary of Hydrology (WMO, 1974; Johannsson, 1984) as the period of time required for storm runoff to flow from the most remote part of a drainage basin to the outlet. This definition has been used in a variety of hy- drological texts (Richards, 1944; Chow, 1964; Haan et al., 1994; Maidment, 1993; Viessman and Lewis, 1995; Musy and Higy, 2004). Wikipedia gives a similar definition (https: //en.wikipedia.org/wiki/Time_of_concentration, last access: 10 March 2020). This basic definition would appear to be clear and unambiguous and, as such, has been widely cited in hydrological analysis and modelling.

There is, however, a problem with the concept of time of concentration in that the way it has been used in practice is generally in conflict with the glossary definition. This confusion is apparent in the multiple definitions and methods of estimation for time of concentration that have been reported in the literature (see, for example, the multiple definitions discussed in McCuen, 2009, and Grimaldi et al., 2012). Some recent reviews of estimation methods have been provided by Fang et al. (2008), McCuen (2009), Wong (2009), Almeida et al. (2014), Gericke and Smithers (2014), Grimaldi et al. (2012), and Michailidi et al. (2018). Methods include the analysis of difference in different measures of timing for effective rainfalls and stormflows; empirical regression equations against catchment characteristics that can be used for ungauged catchments; and direct routing of runoff over the catchment topography and river network using estimated velocities. Grimaldi et al. (2012) even refer to the time of concentration as a "paradox" and suggest that estimates by different methods can vary by $500 \%$.

In fact, the glossary definition reflects a fundamental misunderstanding of hydrological processes that has been part of the history of hydrology for more than 100 years. The issue revolves around what is meant by the verb "to flow" in the standard glossary definition. The utility of the concept of time of concentration lies in its potential to provide an upper limit for the timescale of the hydrograph response of a catchment area. However, it is not the flow velocities that should be used to define the response times in a catchment, 
but the relevant surface, subsurface, and channel flow celerities or wave velocities. It seems that this might first have been suggested by Laurenson (1964), but has since been applied by many others (e.g. Morgali and Linsley, 1965; Eagleson, 1970; Wong and Laurenson, 1983; Beven, 1989, 2012; Wong, 2003; Saghafian et al., 2002; McDonnell and Beven, 2014).

Laurenson $(1964$, p. 146) wrote that

The "drop of water" concept of the runoff process described above is, however, unreal, as water on the ground and in the stream channels does not exist as a collection of drops, but as an amorphous mass. Furthermore, were it possible to label individual molecules of water, it would be found that their paths and velocities of flow vary tremendously; some molecules would have an extremely short travel time, while others would never reach the outlet at all. We must therefore abandon the "drop of water" concept, and consider behaviour of water in the mass.

He did not, however, interpret the response of the amorphous mass explicitly in terms of celerities, but goes on to suggest (p. 147) that " $\ldots$ it is in this sense that the term "travel time" is used in this paper. It is a storage delay time, and implies travel of an effect rather than of a drop of water. The effect is transmitted by both wave movement and translation of the water". He represents the effect by using nonlinear storage elements in the time-area discretization of the catchment area.

It is the celerities or wave velocities that govern the hydrograph response to an input, for both surface and subsurface flows. Celerity is the speed with which a perturbation to a flow will propagate downstream (and in some cases upstream). Celerity will generally be related to velocity but will depend on the flow conditions. It will be different for different input intensities and different for rising limb relative to falling limb discharges. In general it is necessary to make some assumptions about the nature of the flow in order to be able to estimate a local celerity and the time it takes for a perturbation to reach the outlet of a hillslope or catchment (see the Appendix for some simple surface and subsurface examples). It must be stressed that while any numerical difference between velocities and celerities will depend on the mathematical assumptions used (e.g. whether the resultant differential equations are kinematic, parabolic, hyperbolic, or elliptic), the concept of celerity as a wave velocity faster than the flow velocity is the important consideration here. Stated simply, it is the space-time pattern of celerities that controls the outflow hydrograph and the pattern of velocities that will control any conservative transport (e.g. McDonnell and Beven, 2014). This is why the glossary definition should not be used to derive times of concentration for hydrograph prediction.
For the case of a dry initial condition and a steady input rainfall, the time from the start of rainfall to peak response is usually called the time to equilibrium and is obtained by integrating the celerity from upslope at time to $t=0$ to a downslope outlet. Eagleson (1970), for example, gives equations for time to equilibrium for surface runoff and refers to it as the time of concentration. Beven (1982a, b) does the same for subsurface flows and also refers to the time to equilibrium as the time of concentration. Wong $(2003,2009)$ treats the time of concentration as being equivalent to the time to equilibrium. In effect, this is how the time of concentration has often been used in practice when applied to the analysis and prediction of hydrographs, even if many explanations of the concept are still presented in terms of velocities rather than celerities. This is a result of the historical development of the concept which the following text will explore in more detail.

\section{Early concepts of time of concentration}

Mulvany $(1851$, p. 23) notes the importance of "the time which a flood requires to attain its maximum height during the continuance of a uniform rate of fall of rain". He also notes that (p. 24) "This question of time, as regards any catchment, must depend chiefly on the extent, form and rate of inclination of its surface". Mulvaney goes on to discuss the possibility of having a self-registering (recording) rainfall and stream gauges that would allow the development of relationships for estimating peak discharges in different circumstances. A little later, Kuichling (1889) was perhaps the first to define explicitly a time of concentration as the time taken for water to enter into and flow from the furthest impermeable surfaces contributing to an urban drainage system.

The Elements of Hydrology text of Adolf Frederick Meyer (1917) ${ }^{1}$, in the section Flood due to Rainfall, states that "In general, the maximum flood due to rain will result from the greatest amount of most unfavorably distributed precipitation which may be expected to occur over the entire tributary watershed within the time required for water from the remotest portion of the drainage basin to reach the point of observation. The time of concentration, in turn, depends upon the topography of the watershed and the size and slope of the water course" (pp. 309-310). Meyer provides no further explanation, which implies that this was already a term commonly understood by hydrologists and hydraulic engineers. Certainly, engineers designing drainage systems referred to the point of concentration at the end of a pipe system. Lloyd-Davies (1906) defines the time of concentration for urban drainage as the sum of a time of entry and time of flow, suggesting that "if the velocity of flow for the various lengths of sewer is assumed to be equal to that ob-

\footnotetext{
1(1880-1962); see http://www.history-of-hydrology.net/ mediawiki/index.php?title=Meyer,_Adolf_Frederick (last access: 22 May 2020).
} 
taining when they are one-half full, [the time of flow] can be estimated with sufficient accuracy for all practical purposes" (p. 47). Meyer (1917, p. 146) also notes the requirement to estimate the lengths of time required for the runoff from a given precipitation to reach various points of concentration in a sewer system. Richards (1944, p. 33) defines this for a schematic catchment as the "period of concentration". The use of velocities in the estimation of time of concentration for drainage systems has continued to the present day. The textbook of Butler and Davies (2010), for example, suggests using the average velocity when a pipe is just full to estimate the time of flow. Of course, when the pipes really are full, the celerities will be much faster than the velocities, subject only to head loss in surcharging at points open to atmospheric pressure. Such factors are only considered in detailed modelling of sewer systems, not in the classic time-area approaches based on time of concentration, all of which seem to be have been based on flow velocity estimates, albeit with different choices of an appropriate velocity.

Given that time of concentration depends on the characteristics of flow pathways within a catchment, it is simple common sense to consider the distributed nature of those flow pathways in estimating catchment responses. It is also common sense that the spatial patterns of rainfall and snowmelt inputs will affect the magnitude and timing of river discharges. It is not therefore surprising that these factors have been incorporated into hydrograph models for well over a century, even though the possibilities for doing so were limited by the availability of data and computational power in the days when computers were people.

The first such distributed model for a catchment (that I know of) was proposed by Edouard Imbeaux (1892) ${ }^{2}$ for providing flood forecasts ("Essai d'organisation d'un système d'annonce hydrometrique") for the Durance River in southeastern France following a series of large events in the Durance and Rhône in the period 1873-1890 (as well as major floods in 1843 and 1856). Imbeaux discretized the Durance catchment into zones of travel time to a point at which flood discharge predictions were required and also elevation zones to allow for differences in rainfalls, the pattern of seasonal snowmelt, and consequent runoff generation. By applying a form of degree-day snowmelt model and a simple local runoff coefficient in each of his discretized elements, the resulting storm runoff could be routed to the point of interest according to the specified time delays for each element. He expresses the concept in terms of routing water particles: "notre molécule glissant depuis le pointe de sa chute jusqu'en $A$ " (where $A$ is the point of interest). The result is what we would now call a time delay histogram or time-area histogram for routing runoff to the channel and then to the outlet.

\footnotetext{
2(1861-1943); see http://www.history-of-hydrology.net/ mediawiki/index.php?title=Imbeaux,_Edouard (last access: 22 May 2020).
}

Imbeaux recognized that the runoff coefficients would vary with both season and geology. He also proposes that the runoff coefficient would increase with mean rainfall intensity and that for large events the soil will be largely already saturated. He also had information on the variation in rainfall totals for events over the Durance basin. In his analysis of travel times he looked at the propagation of the hydrograph peak down the river network for five exceptional events (October 1882, October 1886, November 1886, October 1889 , March 1890) and found some consistency in the travel times, while noting that overbank flows would change the nature of the wave propagation. For surface runoff on the hillslopes he proposes a hydraulic representation for flow velocity as a square root function of flow depth (analogous to the Chezy or Darcy-Weisbach uniform flow relations), where flow depth is expressed as a specified fraction of rainfall depth in a time step. He also introduces a rule of superposition to allow for variations of rainfall intensity in different time steps and effectively introduces a time of concentration related to the longest particle travel time ("le temps que met la molécule la plus lente à faire son trajet") as the number of hourly time step areas ("courbes horaires") required to represent the total response of the catchment.

Imbeaux realizes the approximate nature of his analysis, particularly in terms of assuming prior saturation of the soil so that there may be a delay in the response if that is not the case. He also notes that the end of the storm might be limited by the infiltration of surface water into the soil, shortening the duration estimated from the time delay histogram. The importance of calculating effective storm runoff when there is rain on snow or rain with snow at higher elevations is also noted. He also regrets that the rainfall data from past events do not allow an analysis of the effects of rainfall variability over time, as he only has daily totals available.

This rather remarkable study has all the elements of a modern distributed model, albeit simplified in terms of the resolution of the discretization and the nature of the runoff generation and routing methods employed. Imbeaux was not alone, however, in taking such an approach. Apparently independently (he makes no reference to the earlier work of Imbeaux in France or Lloyd-Davies in the UK), Ross (1921; reproduced in Loague, 2010) in Australia produced a similar time-area histogram approach to hydrograph prediction (see Fig. 1). He notes that for constructed drainage schemes, "All sewers and channels are designed for definite velocities, therefore starting from the discharge point for the whole system it is quite easy to fix points on all pipes, channels, gutters etc., that are at the required time intervals from the discharge point." For natural catchment areas, for "rivers, rivulets and creeks [...] the velocities of flow can be found experimentally, and thus all points where time contours cross water courses can be accurately fixed". He then suggests that for the hillslopes, lines can be drawn between these points "after examination of the country using the formula velocity $=C \sqrt{r s}=k \sqrt{s}$ where $s$ is the average slope between the 


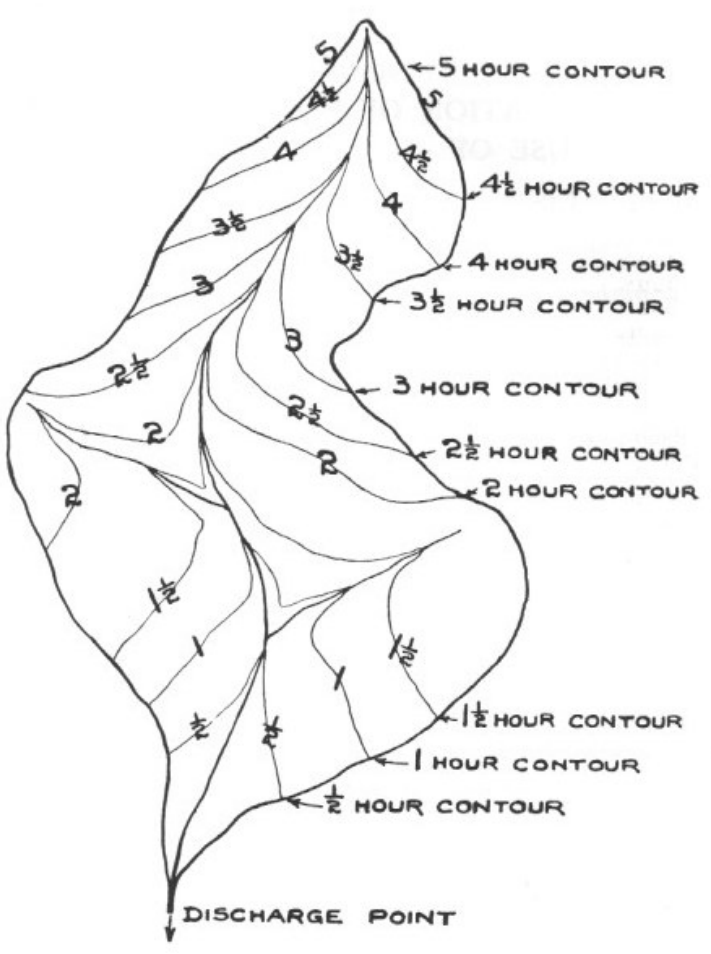

Figure 1. Schematic time delay contours or isochrones of travel time in a catchment based on velocities (after Ross, 1921, p. 86). He states that "A time contour line may be defined as a line drawn on the plan from all points on which water would take the same time to flow to the discharge point for the area." (Ross, 1921, p. 85).

two time contours considered. Values of $k$ would be required for the different classes of country..." (p. 91). This is really rather similar to some forms of topographic analysis using digital elevation models carried out today. Similar forms of time delay histogram to distributed hydrological models were developed by Zoch (1934), Turner and Burdoin (1941) and Clark (1945) in the US, and Richards (1944) in the UK.

In each case, the time of concentration of a catchment was implicit in the number of time delay histogram elements used in representing that catchment. In the simplest case, the velocities used to transform distances into time delays were assumed constant, for simplicity of computation, resulting in simple linear superposition of the delayed runoff from each element. Imbeaux (1892) did allow for velocity to vary nonlinearly with runoff magnitude on the hillslopes, but this can introduce difficulties under some circumstances if simple superposition is used (if runoff generation is higher in the upper part of a catchment, it might be calculated as arriving at the outlet before runoff generation from the lower part of the catchment). Clark (1945) did include a linear storage function in his time-area routing as a way of modifying the skewness of the resulting hydrograph to be more positive. Processing discharges through a storage, with an appropriate choice of time constant, can be used to effectively modify velocities to celerities (though Clark did not justify the method in this way). Hjelmfelt (1984) compares the Clark method with an approach based on kinematic wave celerities and shows that the Clark method can mimic a nonlinear kinematic wave on a simple geometry.

\section{Leroy K. Sherman and the unit graph}

The time delay histogram approach of Imbeaux, Ross, Zoch, Clark, and Richards has a number of inherent difficulties in determining the areas in each time delay element, both in terms of defining the flow pathways to give the distances and the effective flow velocities (or more correctly celerities) to transform distance into time, especially if that transformation might depend on flow rates in some nonlinear manner.

Some of those difficulties were overcome by generalizing the time delay histogram to a catchment-scale transfer function derived from observed hydrographs. This generalization was first proposed by Leroy Kempton Sherman ${ }^{3}$ in 1932 as the unit-graph method. The transfer function relates a unit of effective rainfall as input to the same volume of storm runoff as output. "The term effective rainfall means rain producing surface runoff" (Sherman, 1932; also reproduced in Loague, 2010). He suggested that under some simplifying assumptions, "By making use of a single observed hydrograph, one due to a storm lasting one day, it is possible to compute for the same watershed the runoff history corresponding to a rainfall of any duration or degree of intensity" (Sherman, 1932, p. 54). Those assumptions include the stationarity of the unit graph; linearity with respect to effective rainfall or storm runoff in excess of baseflow; and superposition of the contributions from successive inputs of storm runoff. Sherman does address the issue of how much of the rainfall should be considered effective rainfall or storm runoff. He notes that "percentages of runoff ... appear to be very erratic" (Sherman, 1932, p. 57), but derives graphs of percentage runoff against storm rainfall for several catchments (see also Sherman, 1940). He also shows how to allow for the effects of prior rainfalls, noting that the approach is "rational, but the rule is empirical and only roughly approximate" (Sherman, 1932, p. 58).

The unit-graph approach is now more commonly known as the unit hydrograph method and is still widely used. Time of concentration has been considered important to the unit hydrograph method in that it can be used to define the temporal support for the unit hydrograph, often appearing as a parameter in defining some functional form, such as the triangular unit hydrograph. The triangle was first suggested as a simplification of the true time delay histogram by Zoch (1934) so that he could derive analytical solutions for hydrograph prediction from sequences of effective rainfalls when calculations had to be done by hand. A similar approach was taken in the Snyder synthetic unit hydrograph (Snyder, 1938). The

\footnotetext{
${ }^{3}(1869-1954)$
} 
triangle was later suggested as a good approximation by the work of O'Kelly (1955) in Ireland; incorporated into the general linear theory of Dooge $(1959)^{4}$; and later used widely, for example in the UK Flood Studies Report (FSR; NERC, 1975) and Flood Estimation Handbook (FEH; Institute of Hydrology, 1999).

It has the advantage that only two parameters (three if an initial lag is needed) are required to define the shape of the triangle since the volume is constrained by definition to unity. Thus given a time to peak and a time of concentration the triangle is fully defined. This can be reduced to a single parameter if, as in the FSR and FEH, it is assumed that there is a fixed ratio between them. Alternatively, given a time to peak and peak flow, the time of concentration, as the basal temporal support of the unit hydrograph, can be calculated and does not need to be estimated separately.

It is worth noting at this point that however the unit hydrograph is derived, when integrated in time (known as the "S curve" in unit hydrograph theory) it provides a theoretical definition of the rising limb of the equilibrium hydrograph from a continuous steady input. The unit hydrograph is in fact serving as a transfer function to transform the impact of a unit of effective rainfall over the hillslope into a hydrograph form. As recognized by Laurenson in 1964 (in the earlier quotation) and Morgali and Linsley (1965) this is not the same as water droplets flowing to the outlet, even for the case of purely surface runoff. It is also not the same as a time to equilibrium that would be defined by the rising limb celerities under a continuous steady input, since a unit hydrograph derived from observations implicitly includes the nonlinear effects of falling limb surface and subsurface celerities (e.g. Eagleson, 1970; Beven, 1982a, b), which can be expected to vary with input intensities (and antecedent conditions in the case of subsurface responses). To consider the unit hydrograph as a stationary linear transfer function for a catchment will, therefore, be an approximation, albeit that the stationarity assumption has often proven rather successful in real-world applications (at least after mass balance is used to constrain the effective rainfalls in the analysis of hydrographs). Ben-Zvi (1974) notes that linearity of the time-area histogram will hold under any assumption that velocities are constant with flow rates at every point in a catchment. Actually, this might be more likely to be approximately true for flow celerities; see Eq. (A19).

There is an enormous literature on methods of deriving unit hydrographs from observed rainfall and discharge data (including recent data-based transfer function methods that allow for some nonlinearity, e.g. Young, 2013) and fitting simple parametrically parsimonious forms, such as the triangle or gamma function. The advantage of using simple functions of this type is that the fitted parameters derived can be

\footnotetext{
4(1922-2010); see http://www.history-of-hydrology.net/ mediawiki/index.php?title=Dooge,_JCI_(Jim) (last access: 22 May 2020).
}

empirically related to catchment characteristics. The aim in doing so is to be able to estimate unit hydrographs for ungauged catchments, using parameters derived from gauged catchments. This has included many studies that relate a time of concentration to catchment characteristics, starting with the regression approach of Kirpich (1940) for catchments dominated by channel flow. The Kirpich equation has the form

$t_{\mathrm{c}}=0.0078\left(L^{2} / S\right)^{0.385}$

where $L$ is the length of the main channel and $S$ is the slope. Kirpach did not derive the time of concentration from flow velocities, but from the translation of observed hydrographs. Thus this time of concentration is effectively based on celerities and not velocities. Later the work of Nash (1959) in deriving such relationships was the basis for the approach taken in the FSR and FEH in the UK. There are many others. Reviews of such approaches comparing estimates from different methods continue to the present day (e.g. Fang et al., 2008; Grimaldi et al., 2012; Gericke and Smithers, 2014; Michailidi et al., 2018) but without any clear discussion of velocities and celerities in the consideration of different methods and the subsequent estimates. It is therefore not surprising that different methods of estimating time of concentration can vary widely.

\section{Reconnecting to catchment topography - the GIUH}

The unit hydrograph moved the analysis of the impulse response of a catchment away from the spatial topographic characteristics of the time delay histogram to a more generalized functional form. Starting in 1979, Ignacio RodriguezIturbe and his colleagues started to reintroduce catchment geomorphology in the form of the geomorphological unit hydrograph (GUH; Rodriguez-Iturbe and Valdes, 1979; Rodriguez-Iturbe et al., 1982). The aim was ambitious: to provide an overarching theory of the complex interrelationships between runoff generation and the channel network, extending the seminal work of Horton $(1945)^{5}$, to explain the deep regularity of the channel network and catchment form (Rodriguez-Iturbe, 1993).

The GUH was based primarily on a statistical generalization of routing on the hillslopes and in the channel network. For the hillslopes routing was reduced to either assuming an instantaneous contribution of overland flow to the nearest channel or effectively a distribution function for the percentage of water drops added instantaneously over a catchment area to reach the outlet of a headwater channel (external network link) at time $t$. A one-parameter exponential distribution has been commonly assumed. The rest of the channel

\footnotetext{
5(1875-1945); see http://www.history-of-hydrology.net/ mediawiki/index.php?title=Horton,_Robert_Elmer (last access: 22 May 2020).
} 
network was handled in a similar way but taking account of the probability of reaches of a given order occurring in the channel network as represented by Horton's laws of basin composition. Using a Strahler ordering definition, ratios of stream numbers, lengths, and areas for different stream orders can be assumed relatively constant. This provides a definition of the probability of water drops moving from one stream order to the next. A function for waiting times of droplets within each state can also be assumed, commonly again an exponential distribution for simplicity. The result is a form of cascade of exponential distributions, but modified to allow for the order characteristics of the channel network.

Note that in this formulation, the nature of the response was still expressed in terms of the probabilistic movement of conceptual water droplets. The integral of the instantaneous response function over time is then a time to equilibrium under a continuous steady input of effective rainfall. This is conceptualized, however, as a time of concentration allowing for the furthest water droplets to arrive at the outlet (although under the exponential store assumptions the theoretical time to equilibrium is infinite such that definition of a finite time to equilibrium or concentration would therefore require truncation of the GUH at some point).

The timescale of the GUH also requires some additional assumption. Horton's laws relate reach numbers, lengths, and areas to stream order, but do not give a relationship that allows a time scaling. In one sense this does not matter in that the parameters of the distribution functions of the theory can be fitted to data as time constants. However, taking advantage of work by Leopold and Maddock (1953) that showed that mean stream velocities increase only slowly with catchment area and stream order, it is possible to relate length characteristics to time under the simple assumption of a constant mean stream velocity. Rodriguez-Iturbe and Valdes (1979), by assuming that the GUH could be expressed as a triangle, carried out a regression analysis over a wide range of theoretical responses to identify equations for peak flow and time to peak of the response function that involve the Horton ratios, stream order lengths, and the mean stream velocity. The mass balance constraint under the triangular assumption means that time of concentration does not need to be considered explicitly; it is defined by the peak flow and time to peak. Rosso (1984) fitted a two-parameter gamma distribution (equivalent to the Nash cascade of linear stores) to the GUH transfer function where the time constant parameter also involves the mean stream velocity but which can also be fitted directly to observed effective rainfall and direct runoff data. Note that this is still being expressed in terms of velocities rather than celerities, even though fitting to time to peak actually implies the use of celerities.

Rodriguez-Iturbe et al. (1982) noted that because of this velocity parameter, the GUH might be expected to vary from event to event and also within an event. They suggested, based on model results, that for any given event, the GUH could be characterized by the velocity at the peak flow. Later work served to replace the velocity parameter with its dependence on the intensity and duration of the rainfall excess in what was called the geomorphoclimatic theory of the instantaneous unit hydrograph (Rodriguez-Iturbe et al., 1982). In the derivation, kinematic wave theory is used to predict the peak flow velocity in a given channel order given storm intensity and duration, under the assumption that the effective rainfall is of sufficient duration to exceed the time to equilibrium of a first-order stream (this was later relaxed by Nowicka and Soczynska (1989), who extended the analysis to partial-equilibrium hydrographs). Storm intensities and durations will vary from storm to storm however and, under assumptions about their distribution, the stochastic distribution of the GUH peaks and time to peaks can be obtained by derived distribution theory (e.g. Rodriguez-Iturbe, 1993). This can be taken further to determine the flood frequency characteristics, given some functional way of estimating effective rainfall for an event from rainfall statistics (e.g. the infiltration capacity method used in the derived distribution approach of Eagleson, 1970).

There are three features to note, in general, about the GUH approach. The first is that it deals primarily with the channel routing component of catchment response. It does not explicitly deal with how much of the rainfall becomes effective rainfall, except in the infiltration excess approach to estimate flood frequencies by derived distributions noted above (Beven, 1986). The second is that although there is a time of concentration implied by the triangular approximation to the impulse response used in the regressions against basin-order ratios, it is never explicitly considered because of the mass balance constraint. This is perhaps just as well given that the full expression of the GUH has an infinite tail.

Thirdly, there is the treatment of the velocity parameter that provides the time scaling of the impulse response. Throughout the GUH literature this is expressed as a mean channel flow velocity. When the velocity is allowed to vary with storm characteristics, the mean channel flow velocity at the peak has generally been used. Where the kinematic wave approximation to the velocity-discharge relationship was invoked, at the first-order basin scale the peak mean channel flow velocity at the time of equilibrium was determined. This is somewhat ironic, because estimating that time to equilibrium in a headwater involves a kinematic wave celerity (as given by Henderson and Wooding, 1964; Morgali and Linsley, 1965; and Eagleson, 1970), but the use of the maximum velocity still seems to invoke thinking that is firmly rooted in the velocities and travel times of water droplets in overland flow rather than wave velocities or celerities. It also takes no account of falling limb celerities. GUH theory therefore consistently muddles these different concepts. The historical context is perhaps important here. The GUH is still based on thinking about stormflow as a surface runoff, but in the same year that the first GUH papers appeared, Sklash and Farvolden (1979) published their environmental isotope tracer paper that showed that hydrographs could be dominated by 
stored water and that overland flow could be pre-event stored water displaced by the storm rainfall inputs. This paper had a greater effect on perceptual models of catchment response than some of the earlier tracer and geochemical-based work on stored water contributions to the hydrograph.

\section{The coming of digital elevation data: distributed time of concentration calculations}

One of the reasons for the generalizations of the UH and GUH approaches to modelling catchment responses was that before the 1980s there was no general access to digital terrain data or digital elevation models (the topographic analysis that underlay the topographic index used in Topmodel, for example, was originally carried out manually; see Beven, 2012). Once such data did become available it also became possible to consider catchment geomorphology more directly in calculating times of concentration on a more distributed basis. The most common approach was to use gridded topographic data, with a calculation of incremental travel times in each grid and channel reach. It seems that in doing so there was again a general confusion as to what velocities should be used in such a calculation, while in practical applications the velocity was again used as a calibration parameter.

Zuazo et al. (2014) provide a general review of these approaches, together with a comparison of methods applied to some hypothetical cases. For their study, they define the time of concentration as "the time at which the catchment or plane is in equilibrium or equivalently the travel time to the downstream end of the plane $(x=L)$ of a wave originating at the upstream end of the plane" (Zuazo et al., p. 1318), noting that solutions for this time to equilibrium based on wave velocity or celerity had been previously given by Morgali and Linsley (1964), Eagleson (1970), and Singh (1976). They conclude that it is important to take account of upslope inputs to have a more robust estimate of the resulting unit hydrograph to avoid additional sensitivity to grid size and input rates. Aron et al. (1991) apply kinematic wave celerities to determine what they call the time of concentration on a fractal topography from hillslopes to rills to a channel network. Saghafian et al. (2002) also base their distributed time delay histogram on estimated celerities for surface runoff and provide one of very few discussions of the difference between using velocities and celerities (see also Wong (2003) for the single flow plane case). They note that their calculations can take account of spatial variability in effective rainfalls and result in time-area histograms that are non-stationary with flow conditions.

In contrast, other recent studies continue to approach the time of concentration from the point of view of the International Glossary definition based on velocities (e.g. Grimaldi et al., 2010; Du et al., 2009). Manoj and Xing (2014) and $\mathrm{Li}$ et al. (2018) use particle tracking techniques based on calculated distributed velocity fields to determine the travel times of water particles, with time of concentration estimated from the longest travel times. The use of velocities in such distributed approaches is specifically criticized by Saghafian and Noroozpour (2010).

\section{Velocities, celerities, and the time of concentration}

This discussion of the historical development of the time of concentration concept has demonstrated that the considerable confusion over the use of the term still persists. As noted earlier, I have been part of that problem. In the papers of Beven (1982a, b) time to equilibrium is correctly used in assessing the hydrograph responses but, following Eagleson (1970), is referred to as time to concentration, thus conflicting with the WMO Glossary definition. In contrast, other studies have evaluated time of concentration from flow velocities but have then used this as if it were a time to equilibrium in predicting hydrograph responses. Returning to Imbeaux (1892), he effectively used velocity estimates in his subcatchments and celerities in the channels.

If we are interested in hydrograph responses, it should be clear that we should be not so much concerned with the time of travel of an input water particle from the farthest reaches of the catchment to the outlet as with the time it takes for the effect of that input to have an effect on the output. This is a function of celerity rather than velocity, where celerity is the speed at which perturbations to the flow can move through the system. Thus, for clarity, it is necessary to replace reference to velocities by reference to celerities or wave velocities. The nonlinear changes in celerity over the course of a hydrograph are partly what lead to the asymmetry of hydrograph shape. Thus any interpretation of the unit hydrograph in terms of travel times of water particles neglects the changing nature of the celerities over the rising and falling limbs of the hydrograph. Note, however, that the dependence of celerity on flow magnitude also suggests that the linearity assumptions of the unit hydrograph and its time of concentration support will not be generally valid, as previously recognized in the geomorphoclimatic UH theory. The most widely cited example of this is the demonstration of the change in unit hydrograph with peak discharges in a small catchment by Minshall (1960). However, as Imbeaux showed in his analysis of flood peaks in the Durance, the assumption of a constant celerity might at least sometimes be a useful first-order approximation. This was also shown for the case of the channel tracing experiments of Pilgrim (1977) and for upland channel reaches by Beven (1979a), for one particular velocitydischarge function, albeit that velocities change nonlinearly with discharge (see Eqs. A18 and A19).

We should also expect an effect of catchment scale and the relative importance of runoff production for hillslopes and channel routing. One feature of the time-area histogram, when calculated for natural catchments, is that it tends to show a negatively skewed shape. This can be even more so if 
only the width function of the channel network is considered. Thus, application of a constant celerity assumption will then produce a negatively skewed unit hydrograph. Most derived unit hydrographs are, however, positively skewed (e.g. Sherman, 1932; Snyder, 1938). It has already been noted how Clark (1945) introduced the concept of routing the output from the time-area histogram through a linear store as a way of making the skewness of the resulting hydrograph more positive. At small catchment scales, positively skewed hydrographs might result from long-tailed hillslope hydrographs, particularly when subsurface flows are important (e.g. Beven and Wood, 1993; Botter and Rinaldo, 2003; Li and Sivapalan, 2011), but as scale increases, channel hydrodynamics and the spatial variability in inputs will become more important (Beven and Wood, 1993). In particular, Collischonn et al. (2017) have recently shown that where celerity grows rapidly with discharge, the hydrograph will tend to be more positively skewed, while Fleischmann et al. (2016) demonstrate that the decline in celerity as overbank flows spill onto floodplain areas can produce a tendency towards negative skew. Changes in celerity with discharge can therefore be complex, but where discharge data are available from multiple gauging stations they can be derived from data (e.g. Wong and Laurenson, 1983).

\section{Mathematical celerities and natural hillslopes}

The quantitative analysis of the difference between velocity and celerity responses presented in the Appendix is intentionally simple. It is intended to make it quite clear for pedagogical purposes why the traditional definition of time of concentration is inconsistent with the way in which it is commonly used in practice. It has been used in the past to relate estimates of time to equilibrium to hillslope form expressed in terms of convergence and convexity (e.g. Morgali and Linsley, 1965; Singh, 1976; Hjelmfelt, 1984; Sabzevari et al., 2013). It is, however, a mathematical result subject to the various sets of assumptions that underly the analytical solutions presented. It therefore begs the question of whether this mathematistry might be applicable to natural hillslopes. The approximations might not be adequate in hillslopes with 3-D patterns of heterogeneous soil and vegetation characteristics, surface roughness and microtopography, preferential flowlines, soil moisture deficits, depths to bedrock and losses through some (sometimes vaguely) defined lower boundary condition. These heterogeneities do suggest that there will be a complex time and space variability in both velocities and celerities, with the potential for different values and different degrees of diffusion in different flow pathways depending on local structures and flow rates.

Given that we now know that in many catchments the water making up the storm hydrograph is water stored in the catchment prior to an event, it would seem that the standard WMO Glossary definition has little relevance to hydrograph analysis. This understanding implies that there is no simple delay mechanism for water flowing towards the outlet, but a complex interaction between event water and stored water. Even for overland flow processes, the distance over which such interactions occur might be rather local (e.g. the suggestion that microtopography can play a role in old water displacement in Iorgulescu et al., 2007, and the estimate of a mean flow path length for surface runoff of $1 \mathrm{~m}$ in the work of Bergkamp, 1998). This means that water falling at the furthest distance from the outlet might not be expected to contribute to the storm hydrograph for that event, even if some overland flow is generated at that point. In fact, such tracer studies suggest that the actual times for water to flow from the furthest point in a catchment to the outlet may, at least in humid catchments, be many years. Indeed, Berghuijs and Allen (2019) have recently suggested that while the storm hydrograph might predominantly be made up of pre-event water, it might still be (on average) younger than the mean residence time of stored water in the catchment (see also Gallart et al., 2020). That stored water will include water that fell far from the outlet in past events.

What therefore can we take from this analysis that might be applicable to natural hillslopes? The basic concept that the response of the hillslope as seen in the hydrograph will be faster than water can flow from the furthest point upslope will hold even in the case of a steady input. Thus, time to equilibrium could be expected to be shorter than time of concentration in the glossary definition (see Appendix). This will hold for both surface and subsurface flows and for all representations of flow processes for which velocity increases with depth of flow or saturation. The difference between celerities and velocities is likely to be very large in soil with a small effective storage deficit above the water table (i.e. in nearsaturated conditions or with a significant capillary fringe).

Similar issues can apply in the unsaturated zone, where the local celerities associated with film flow (including in preferential flow pathways) can also be faster than the local velocities, resulting in the potential for the displacement of stored water (Bogner and Germann, 2019), though in that case there is the issue of whether the local wetting fronts reach the water table before being overtaken by a following drying front, especially where the saturated zone may be deeper in the upper part of a hillslope. In structured soils it is also possible that both mean porewater velocities and celerities will be affected by bypassing in larger voids, such that the effective storage deficit might include infiltration into soil peds.

Thus while it may be difficult to provide a complete description for the flow processes on complex hillslopes, it is suggested that the conceptual consequences of the differences between celerity and velocity responses are important and should be incorporated into hydrological teaching in future. It is also worth noting that since celerities are generally faster than mean areal flow velocities, this is also a (partial) explanation for the displacement of stored water in forming the hydrograph (Beven, 1989; McDonnell and Beven, 2014). 
However, the relevance of the time to equilibrium concept can also be questioned, particularly when rainfall durations are shorter or intensities are nonuniform, because of the expectation that celerities will be different on the rising limb and falling limbs of a hydrograph. Certainly, now that we are much less constrained by computational limitations, it will be better to predict the changing celerities during an arbitrary event directly than determine a unit hydrograph from only the $\mathrm{S}$ curve of the rising limb to equilibrium.

\section{Teaching the concept of time of concentration in future}

In the same way that hydrologists should really avoid using the rather desperate technique of hydrography separation (see the section on choosing a method of hydrograph separation in Beven, 1991), it might be better to avoid the use of time of concentration in the IGH glossary definition and time to equilibrium concepts completely. The idea of a maximum time of travel for a water droplet is an attractive one, but it does not survive critical analysis in terms of predicting hydrographs. It is clear, however, that the use of catchment characteristics to predict a "time of concentration" as a basal temporal support for the unit hydrograph continues to this day as one approach to predicting the response of ungauged catchments.

In one sense this is acceptable in the context of the identification of a suitable transfer function from observations since this will implicitly take account of the relevant celerities in the catchment without invoking any assumptions about water velocities (water velocities only become important if there is an additional requirement to estimate residence and transit times that will generally be much longer than the hydrograph timescale). Where we can go wrong, however, is in keeping any association with the glossary definition of time of concentration in terms of water travel times and in the GUH timescale parameter as a velocity rather than as a celerity.

If it is necessary to discuss the concept of time of concentration therefore, physical correctness requires that the glossary definition be abandoned and replaced by a discussion of celerities and time to equilibrium (while noting that falling limb celerities will be different from those that define a time to equilibrium under a steady uniform input). The kinematic wave theory provides a simple framework for showing how celerities can be greater than velocities and how they might vary for different intensities and durations of rainfall and antecedent conditions. This has already been included in some texts, starting with Eagleson (1970). Checking other hydrological textbooks, Overton and Meadows (1976) and Bedient and Huber (1988) specifically state that time to equilibrium should be used in estimating catchment responses, while Brutsaert (2005) mentions only time to equilibrium and not time of concentration. Hornberger et al. (2010) do not discuss either. Haan et al. (1994), Viessman and Lewis (1995), and Musy and Higy (2004), in contrast, still refer to time of concentration in the glossary definition. This has also continued in the recent papers of, for example, Li et al. (2018) and Michailidi et al. (2018). More embarrassingly, Shaw et al. (2011), following earlier editions, treat time of concentration as the longest travel time based on velocities on both a catchment and in a pipe network while more correctly discussing celerities elsewhere.

In teaching, however, it should also be pointed out that the kinematic analysis presented is rather oversimplified, in that on real hillslopes and channel networks the flow relationships will be more diffusive (kinematic shocks are rare in real flows) and will be spatially variable depending on soil, topography, and input sequences. The hydrograph will then reflect the integral effects of the patterns of inputs and celerities in space and time. What needs to be emphasized, however, is that time of concentration in the glossary definition will be relevant to catchment hydrograph responses only where velocities can be directly related to celerities to estimate the hydrograph response. The frequent reference to time to equilibrium as a time of concentration has only confused the issue in both teaching and practice (and, of course, a steady uniform input is really rather rare in reality anyway). If we can explain the hydrograph responses arising from surface and subsurface flows in terms of time-variable celerities, including the variation with patterns of inputs and antecedent conditions, perhaps both of these terms should be abandoned forthwith in hydrological teaching for the 21 st century. 
Appendix A: Time of concentration and time to equilibrium for flow on a plane or channel reach

To illustrate the difference between time of concentration and time to equilibrium in the simplest way, let us assume that the downslope subsurface and surface flows can be represented by a kinematic approximation defined by simple power-law functions between mean flow velocity at a point, $v$, and depth of flow, $h$ (we ignore the unsaturated zone, but see Beven (1982a, b) for a kinematic treatment of wetting and drying front propagation):

$v=a h^{b}$,

where $a$ and $b$ are parameters. Beven (1982a) gives example parameters for downslope saturated subsurface flows for both power-law and exponential profiles derived from field data. The kinematic wave equation is then defined by combining this function with the continuity equation:

$\varepsilon \frac{\partial h}{\partial t}=\frac{\partial q}{\partial x}+i$

where $q=\int_{0}^{h} v d h$ is the local specific discharge, $i$ is a local input rate, and $\varepsilon$ is an effective storage coefficient for the change in depth of flow with change in storage volume, since, with these definitions, $\frac{\mathrm{d} q}{\mathrm{~d} h}=v$, so that

$\varepsilon \frac{\partial h}{\partial t}=a h^{b} \frac{\partial h}{\partial x}+i$

or

$\frac{\partial h}{\partial t}=c \frac{\partial h}{\partial x}+\frac{i}{\varepsilon}$,

where $c$ is the celerity (with dimensions $\mathrm{L} \mathrm{T}^{-1}$ ), and thus for the power-law-flow relationship when

$c=\frac{a h^{b}}{\varepsilon}$.

For mean Darcian flow in subsurface flow on a slope $\beta$, with distance measured along the slope, and hydraulic conductivity as a power function of depth of saturation,

$a=K_{\mathrm{o}} \sin \beta$,

where $K_{\mathrm{o}}$ is the hydraulic conductivity when $h=1, b$ defines how quickly hydraulic conductivity increases with depth of saturation, and $\varepsilon$ is the storage deficit above the water table per unit depth of rise or fall of $h$.

Then, for the subsurface flow case (assuming that $\varepsilon$ is approximately constant),

$c=\frac{K_{\mathrm{o}} \sin \beta h^{b}}{\varepsilon}$.
For these relationships, at any $h$ the ratio of the celerity and local mean water particle velocity, $v_{\mathrm{p}}$, can be determined where

$v_{\mathrm{p}}=\frac{K_{\mathrm{o}} \sin \beta h^{b}}{n}$,

where $n$ is the porosity of the soil (again assumed constant for simplicity). The local ratio for celerity to mean porewater velocity is therefore $n / \epsilon$, and since the effective storage $\varepsilon$ is always less (and sometimes much less in a wet soil) than the porosity $n$, celerity is always faster than the mean porewater velocity, which itself is greater than the mean Darcian velocity, $v$. Integrating to the length of a flow plane gives the time to equilibrium (dependent on $c$ ) and the time of concentration, here as the integral of mean porewater velocity for drops of water $\left(v_{\mathrm{p}}\right)$, assuming $h=0$ when the recharge $i$ reaches the base of the soil profile at $t=0$ (note that Beven (1982a, b) gives a more complete solution that allows for travel time of a wetting front through the unsaturated zone and filling to saturation for depths when $K_{\mathrm{s}}<i$ ).

Equations (A1) to (A5) set out the basis for evaluating celerities and velocities in subsurface flow on a hillslope plane using kinematic wave theory. Under the simplifying assumptions of a power law and constant values of effective storage and soil porosity, the local ratio of celerity to mean porewater velocity is then given by

$\frac{c}{v_{\mathrm{p}}}=\left\{\frac{K_{\mathrm{o}} \sin \beta h^{b}}{\varepsilon}\right\} /\left\{\frac{K_{\mathrm{o}} \sin \beta h^{b}}{n}\right\}=\frac{n}{\varepsilon}$,

where $n$ is the porosity of the soil. It was noted that since the effective storage $\varepsilon$ is always less (and sometimes much less in a wet soil) than the porosity $n$, celerity is always faster than the mean porewater velocity which itself is greater than the mean Darcian velocity, $v$. Integrating along the length of the plane, we can derive an analytical solution for both the time of concentration and the time to equilibrium:

$$
\begin{aligned}
& \operatorname{TOC}_{v_{\mathrm{p}}}=n\left[\frac{1+b}{K_{\mathrm{o}} \sin \beta}\right]^{\left(\frac{1}{1+b}\right)}{ }_{i}^{\left(\frac{-b}{1+b}\right)}{ }_{L}\left(\frac{1}{1+b}\right), \\
& \operatorname{TTE}_{\mathrm{c}}=\varepsilon\left[\frac{(1+b)}{K_{\mathrm{o}} \sin \beta}\right]^{\left(\frac{1}{1+b}\right)}{ }_{i}^{\left(\frac{-b}{1+b}\right)} L_{L}\left(\frac{1}{1+b}\right)
\end{aligned}
$$

Thus the time of concentration and time to equilibrium are also in a fixed ratio of $n / \varepsilon$ in this case. The wetter the soil, and therefore the smaller the effective storage $\varepsilon$ relative to the porosity $n$, the greater will be the difference between the two response times. Some results for constant values of $\varepsilon$ and different input rates are shown in Fig. A1. It would not be expected that $\varepsilon$ will stay constant during an event, but would be initially low in a wet soil due to any capillary fringe or macroporosity, becoming larger depending on the form of the wetting front during recharge. TOC will, however, necessarily be larger than TTE. 
For the special case of a uniform profile of hydraulic conductivity $(b=0)$, time of concentration and time to equilibrium are no longer dependent on the input rate $i$ (mean porewater velocities and celerities are constant regardless of depth of saturation). Beven (1982a, b) gives more detail for this case in non-dimensional coordinates.

$$
\begin{aligned}
& \operatorname{TOC}_{v_{\mathrm{p}}}=n\left[\frac{1}{K_{\mathrm{o}} \sin \beta}\right] L \\
& \mathrm{TTE}_{\mathrm{c}}=\varepsilon\left[\frac{1}{K_{\mathrm{o}} \sin \beta}\right] L
\end{aligned}
$$

For the case of a confined saturated layer with $\varepsilon \ll n$ (as in a saturated pipe), the celerity will approach infinity.

For surface flow that is treated as a uniform sheet flow that conforms to a Darcy-Weisbach type relationship, mean velocity at any depth of flow is given by

$\bar{v}=C(\sin \beta)^{0.5} h^{0.5}$,

so that

$q=\bar{v} h=C(\sin \beta)^{0.5} h^{1.5}$,

where $C$ is a roughness factor. Note the difference in the definition of $v$ from the subsurface case. Following normal practice, the velocity relationship takes account of the effective porosity for surface flow implicitly in the expression for velocity and water droplets are assumed to travel with an average velocity of $\bar{v}$. These types of kinematic relationship can also be used to derive hillslope and channel times of concentrations analytically, given values of the parameters (e.g. Henderson and Wooding, 1964; Eagleson, 1970; Beven, 1982a, b; Wong and Chen, 1997). In this case celerity as $\frac{\mathrm{d} q}{\mathrm{~d} h}$ is given by

$c=1.5 C(\sin \beta)^{0.5} h^{0.5}$.

Thus

$\frac{c}{v}=\left\{1.5 C(\sin \beta)^{0.5} h^{0.5}\right\} /\left\{C(\sin \beta)^{0.5} h^{0.5}\right\}=1.5$,

so that $c$ will always be greater than $\bar{v}$. Integrating along the plane again gives expressions for the time of equilibrium (dependent on $c$ ) and the time of concentration (here as the integral of mean velocity $\bar{v}$ for drops of water).

$\mathrm{TOC}_{\mathrm{v}}=\frac{3}{2}\left[\frac{1}{C(\sin \beta)^{0.5}}\right]^{2 / 3} i^{-1 / 3} L^{2 / 3}$

$\operatorname{TTE}_{\mathrm{c}}=\left[\frac{1}{C(\sin \beta)^{0.5}}\right]^{2 / 3} i^{-1 / 3} L^{2 / 3}$

Taking the ratio of the two times gives a ratio of 1.5 longer for the time of concentration. Some indicative times are shown in Fig. A2.

Thus in both surface and subsurface flow an input of water can have an impact on the hydrograph more rapidly than the water "droplets" can flow from the farthest distance to the output. Both, however, vary with the intensity of the input. Time of concentrations for surface runoff will vary with the way in which friction losses are expressed, including any allowance for effective porosity when flow is through a vegetation cover. For subsurface flow it will also vary with the hydraulic conductivity profile in the soil (see for example Beven, 1982a, b). Note that in this case we consider only recharge to the water table at the base of a soil profile that is deep enough that the soil does not saturate to the surface. Henderson and Wooding (1964) also considered a diffusive wave solution for steady-state subsurface flow, with different downstream boundary conditions, but did not derive expressions for the time of concentration or equilibrium.

For channel flows, the 1-D St.-Venant equations are hyperbolic partial differential equations that have both upstream and downstream characteristics in sub-critical flow conditions. In this case the downstream dynamic celerity is locally given by

$c=v+\sqrt{g h}$,

where $g$ is the acceleration due to gravity. Thus, $c$ will again always be greater than the mean cross-sectional flow velocity, but this will depend on the cross-sectional average depth. For a given velocity, the deeper the flow, the greater the ratio $c / v$ will be. In real channels, however, this dynamic celerity might be dominated by the kinematic effect of volume filling, $\mathrm{d} Q / \mathrm{d} A$, both within the 3-D channel form and particularly as the flow goes overbank and spills onto floodplain areas.

For small rough headwater channels for which the kinematic wave equation might still be a useful approximation, Beven (1979a) also showed that the change in velocity with discharge $Q$ could be described by

$v=\frac{Q}{A}=Q\left\{\frac{a}{Q+k}\right\}$,

where $a$ and $k$ are parameters and $A$ is the local crosssectional area of the channel. Support for this type of relationship in small channels is also given by Fig. 2 of Pilgrim $(1977)^{6}$. For this specific function the celerity is

$c=\frac{\mathrm{d} Q}{\mathrm{~d} A}=a$.

This is one example of where the time to equilibrium for a headwater channel reach of length $L$ could be considered constant for all discharges while reflecting a nonlinear velocity discharge relationship (see also Beven and Wood, 1993).

\footnotetext{
6(1931-2015); see http://www.history-of-hydrology.net/ mediawiki/index.php?title=Pilgrim,_David_H (last access: 22 May 2020) and, for somewhat larger flows, Fig. 1.4 of Kirkby, 1993).
} 
Thus there is still a difference between the time to equilibrium and time of concentration as

$\mathrm{TTE}_{\mathrm{c}}=\frac{L}{a}$.

The time of concentration in this case will depend on the flow from upstream, $Q_{\mathrm{o}}$, and rates of lateral inflow per unit length, $q_{1}$. Integrating the inverse of velocity from an upstream discharge of $Q_{o}$ to a downstream discharge of $Q_{0}+L q_{1}$ gives a time of concentration

$\mathrm{TOC}_{\mathrm{v}}=\frac{L}{a}+\left[\frac{k}{q_{1} a}\left\{\ln \left(Q_{\mathrm{o}}+L q_{1}\right)-\ln Q_{\mathrm{o}}\right\}\right]$.
Since $a$ is an asymptotic velocity at high discharges in this case, the time of concentration will approach the time to equilibrium at high flows. This is illustrated in Fig. A3.

Note that these determinations of both time of concentration and time to equilibrium are dependent on an assumption of a continuous uniform rainfall. They thus are representative only of rising limb velocities and celerities. For full hydrograph prediction it will also be necessary to take account of the nonlinear nature of falling limb celerities. 


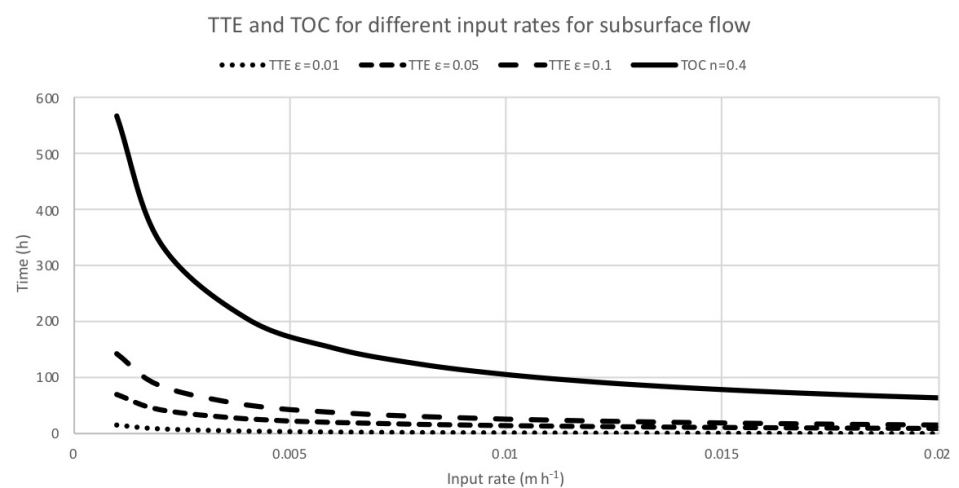

Figure A1. Time of concentration (TOC, solid line) and time to equilibrium (TTE, dashed lines) for subsurface flow on a hillslope of $100 \mathrm{~m}$ for different input rates and values of effective porosity (TOC is constant for each input rate) $\left(K_{\mathrm{O}}=2 \mathrm{~m} \mathrm{~h}^{-1}\right.$, $\left.\sin \beta=0.05\right)$ (Eqs. A7 and A8).

TTE and TOC for different input rates for surface flow

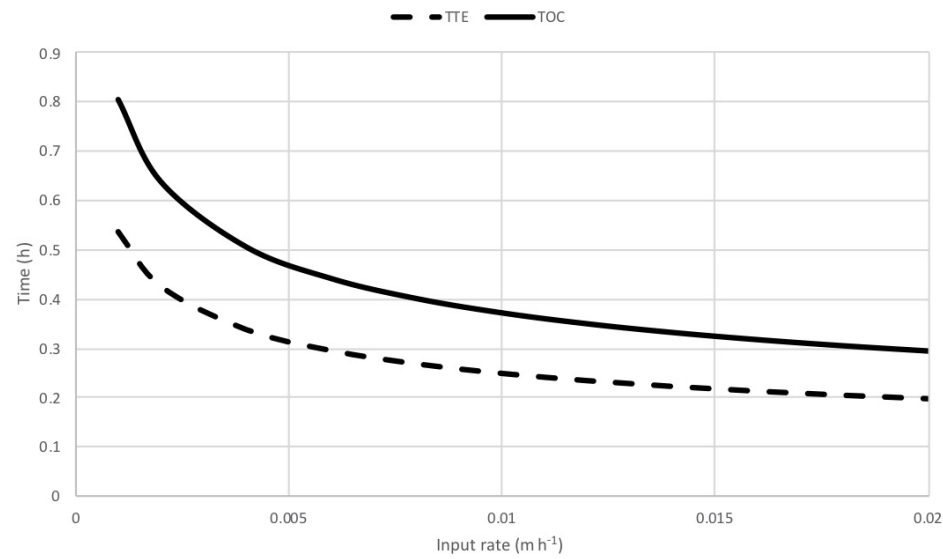

Figure A2. Time of concentration (solid line) and time to equilibrium (dashed line) for surface flow on a hillslope of $100 \mathrm{~m}$ for different values of the input rate $\left(C=10 \mathrm{~m}^{0.5} \mathrm{~s}^{-1}, \sin \beta=0.05\right)$ (Eqs. A15 and A16).

TOC and TTE versus discharge at reach outlet

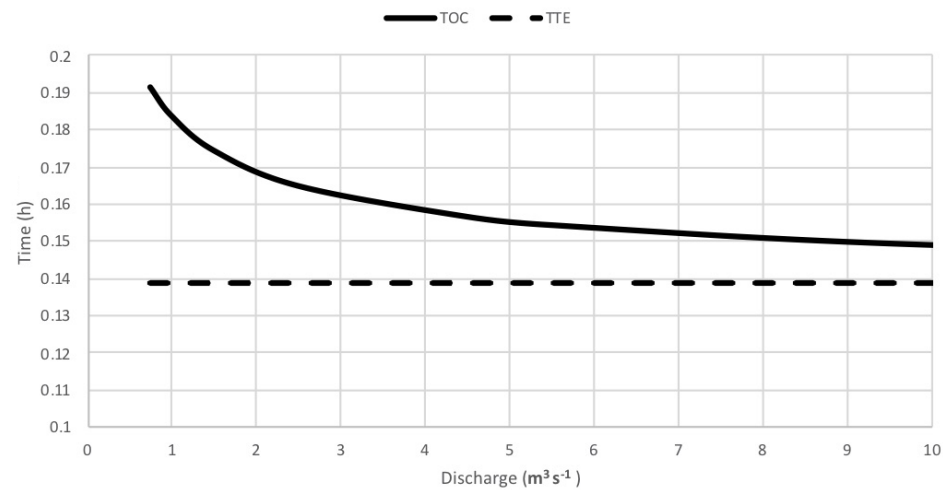

Figure A3. Time of concentration (solid line) and time to equilibrium (dashed line) for an upland channel reach of $500 \mathrm{~m}$, with parameters from Beven (1979a) $\left(a=1 \mathrm{~m} \mathrm{~s}^{-1} ; k=0.233 \mathrm{~m}^{3} \mathrm{~s}^{-1}\right)$. Upstream discharge $0.5 \mathrm{~m}^{3} \mathrm{~s}^{-1}$; lateral inflows from 0.0005 to $0.02 \mathrm{~m}^{2} \mathrm{~s}^{-1}$ (Eqs. A20 and A21). 
Code and data availability. An Excel spreadsheet containing the calculations for the figure included in the Appendix is available from the author.

Competing interests. The authors declares that he has no conflict of interest.

Special issue statement. This article is part of the special issue "History of hydrology" (HESS/HGSS inter-journal SI). It is not associated with a conference.

Acknowledgements. Keith J. Beven would like to thank Charles Obled for bringing the work of Edouard Imbeaux to his notice and providing pdfs of the relevant pages of the 1892 paper. Thanks are also due to Walter Collischonn of the Instituto de Pesquisas Hidraulicas, Porto Alegre, Brazil, who raised my awareness of the work on hydrograph skewness. This paper was instigated by considering the problem of changing catchment responses under natural flood management projects in the Q-NFM project led by Nick Chappell of Lancaster University.

Financial support. This research has been supported by the NERC (grant no. NE/R004722/1).

Review statement. This paper was edited by Maurits Ertsen and reviewed by two anonymous referees.

\section{References}

Almeida, I. K., Almeida, A. K., Anache, J. A. A., Steffen, J. L., and Sobrinho, T. A.: Estimation on time of concentration of overland flow in watersheds: a review, Geociências, 33, 661-671, 2014.

Aron, G., Ball, J. E., and Smith, T. A.: Fractal concept used in timeof-concentration estimates, J. Irrig. Drain. Eng., 117, 635-641, 1991.

Bedient, P. B. and Huber, W. C.: Hydrology and Floodplain Analysis, Addison-Wesley, Reading, Massachusetts, 1988.

Ben-Zvi, A.: The velocity assumption behind linear invariable watershed response models, in: Mathematical Models in Hydrology, 2, IAHS Publication No. 101, IAHS Press, Wallingford, UK, 758-761, 1974.

Berghuijs, W. R. and Allen, S. T.: Waters flowing out of systems are younger than the waters stored in those same systems, Hydrol. Process., 33, 3251-3254, 2019.

Bergkamp, G.: A hierarchical view of the interactions between runoff and infiltration with vegetation and microtopography in semi-arid shrublands, Catena, 11, 201-220, 1998.

Beven, K. J.: On the generalised kinematic routing method, Water Resour. Res., 15, 1238-1242, 1979a.

Beven, K. J.: Kinematic subsurface stormflow, Water Resour. Res., 17, 1419-1424, 1979b.
Beven, K. J.: On Subsurface Stormflow: an analysis of response Hydrolog. Sci. J., 27, 505-521, 1982a.

Beven, K. J.: On subsurface stormflow: predictions with simple kinematic theory for saturated and unsaturated flows, Water Resour. Res., 18, 1627-1633, 1982b.

Beven, K. J.: Runoff production and flood frequency in catchments of order n: an alternative approach, in: Scale Problems in Hydrology, edited by: Gupta, V. K., Rodriguez-Iturbe, I., and Wood, E. F., Reidel, Dordrecht, 107-131, 1986.

Beven, K. J.: Interflow, in: Proc. NATO ARW on Unsaturated Flow in Hydrological Modelling, edited by: Morel-Seytoux, H. J., Kluwer, Dordrecht, 191-219, 1989.

Beven, K. J.: Hydrograph Separation?, in: Proc. BHS Third National Hydrology Symposium, Institute of Hydrology, Wallingford, 3.1-3.8, 1991

Beven, K. J.: Rainfall-Runoff Modelling - The Primer, 2nd Edn., Wiley-Blackwell, Chichester, 2012.

Beven, K. J. and Wood, E. F.: Flow routing and the hydrological response of channel networks, in: Channel Network Hydrology, edited by: Beven, K. J. and Kirkby, M. J., John Wiley and Sons, Chichester, 99-128, 1993.

Bogner, C. and Germann, P. F.: Viscous flow approach to "pushing out old water" from undisturbed and repacked soil columns, Vadose Zone J., 18, 180168, https://doi.org/10.2136/vzj2018.09.0168, 2019.

Botter, G. and Rinaldo, A.: Scale effect on geomorphologic and kinematic dispersion, Water Resour. Res., 39, 1286, https://doi.org/10.1029/2003WR002154, 2003.

Brutsaert, W.: Hydrology: An Introduction, Cambridge University Press, Cambridge, 2005.

Butler, D. and Davies, J. W.: Urban Drainage, 3rd Edn., CRC Press, Boca Raton, 2010.

Chow, V. T.: Applied Hydrology, McGraw-Hill, New York, NY, 1964.

Clark, C. D.: Storage and the Unit Hydrograph, T. Am. Soc. Civ. Eng., 110, 1419-1446, 1945.

Collischonn, W., Fleischmann, A., Paiva, R. C. D., and Mejia, A.: Hydraulic causes for basin hydrograph skewness, Water Resour. Res., 53, 10603-10618, https://doi.org/10.1002/2017WR021543, 2017.

Dooge, J. C. I.: A general theory of the unit hydrograph, J. Geophys. Res., 64, 241-256, 1959.

Du, J., Xie, H., Hu, Y., Xu, Y., and Xu, C.-Y.: Development and testing of a new storm runoff routing approach based on time variant spatially distributed travel time method, J. Hydrol., 369, 44-54, 2009.

Eagleson, P.: Dynamic Hydrology, McGraw-Hill, New York, NY, 1970.

Fang, X., Thompson, D. B., Cleveland, T. G., Pradhan, P., and Malla, R.: Time of concentration estimated using watershed parameters determined by automated and manual methods, J. Irrig. Drain. Eng., 134, 202-211, 2008.

Fleischmann, A. S., Paiva, R. C. D., Collischonn, W., Sorribas, M. V., and Pontes, P. R. M.: On river floodplain interaction and hydrograph skewness, Water Resour. Res., 52, 7615-7630, https://doi.org/10.1002/2016WR019233, 2016.

Gallart, F., von Freyberg, J., Valiente, M., Kirchner, J. W., Llorens, P., and Latron, J.: Technical note: An improved discharge sensitivity metric for young water fractions, Hydrol. Earth Syst. 
Sci., 24, 1101-1107, https://doi.org/10.5194/hess-24-1101-2020, 2020.

Gericke, O. J. and Smithers, J. C.: Review of methods used to estimate catchment response time for the purpose of peak discharge estimation, Hydrolog. Sci. J., 59, 1935-1971, 2014.

Grimaldi, S., Petroselli, A., Nardi, F., and Alonso, G.: Flow time estimation with variable hillslope velocity in ungauged basins, Adv. Water Resour., 33, 1216-1223, 2010.

Grimaldi, S., Petroselli, A., Tauro, F., and Porfiri, M.: Time of concentration a paradox in modern hydrology, Hydrolog. Sci. J., 57, 217-228, 2012.

Haan, C. T., Barfield, B. J., and Hayes, J. C.: Design Hydrology and Sedimentology for Small Catchments, Academic Press, Cambridge, MA, 1994.

Henderson, F. M. and Wooding, R. A.: Overland flow and groundwater flows from a steady rainfall of finite duration, J. Geophys. Res., 69, 1531-1540, 1964.

Hjelmfelt Jr., A. T.: Convolution and the kinematic wave equations, J. Hydrol., 75, 301-309, 1984.

Hornberger, G. M., Raffensburger, J. P., Wiberg, P. L., and Eshleman, K. N.: Elements of Physical Hydrology, The Johns Hopkins University Press, Baltimore, 2010.

Horton, R. E.: Erosional development of streams and their drainage basins; hydrophysical approach to quantitative morphology, Geol Soc. Am. Bull., 56, 275-370, 1945.

Imbeaux, E.: La Durance. Régime, crues et inondations, Annales des Ponts et Chausées, Mémoires et Documents, 7e series (Tome III), Ecole des Ponts et Chaussées, Paris, 5-200, 1892.

Institute of Hydrology: Flood Estimation Handbook (5 volumes), Wallingford, UK, 1999.

Iorgulescu, I., Beven, K. J., and Musy, A.: Flow, mixing, and displacement in using a data-based hydrochemical model to predict conservative tracer data, Water Resour. Res., 43, W03401, https://doi.org/10.1029/2005WR004019, 2007.

Johansson, I. (Ed.): Nordic Glossary of Hydrology, Almqvist and Wiksell International, Stockholm, 1984.

Kirkby, M. J.: Network Hydrology and Geomorphology, in: Channel Network Hydrology, edited by: Beven, K. J. and Kirkby, M. J., John Wiley and Sons, Chichester, 1-11, 1993

Kirpich, Z. P.: Time of concentration of small agricultural watersheds, Civ. Eng., 10, 362, 1940.

Kuichling, E.: The Relation between Rainfall and the Discharge in Sewers in Populous Districts, Trans. ASCE, 20, 1-56, 1889.

Laurenson, E. M.: A catchment storage model for runoff routing, J. Hydrol., 2, 141-163, 1964.

Leopold, L. B. and Maddock Jr., T.: The hydraulic geometry of stream channels and some physiographic implications, US Geol. Surv. Prof Pap. 252, United States Geological Survey, Washington, D.C., 1953.

Li, H. and Sivapalan, M.: Effect of spatial heterogeneity of runoff generation mechanisms on the scaling behavior of event runoff responses in a natural river basin, Water Resour. Res., 47, W00H08, https://doi.org/10.1029/2010WR009712, 2011.

Li, X., Fang, X., Li, J., KC, M., Gong, Y., and Chen, G.: Estimating time of concentration for overland flow on pervious surfaces by particle tracking method, Water, 10, 379, https://doi.org/10.3390/w10040379, 2018.

Lloyd-Davies, D. E.: The elimination of storm water from sewerage systems, Proc. Inst. Civ. Eng., 164, 41-67, 1906.
Loague, K.: Rainfall-Runoff Modelling, in: IAHS Benchmark Series in Hydrology, No. 4, IAHS Press, Wallingford, UK, 2010.

Maidment, D. R.: Handbook of Hydrology, McGraw-Hill, New York, 1993.

Manoj, K. C. and Xing, F.: Estimating the time of concentration of overland flow on an impervious surface using a particle tracking model, edited by: Huber, W. C., in: World Environment and Water Resources Congress 2014, ASCE, Reston, VA, 30-37, 2014.

McCuen, R. H.: Uncertainty analyses of watershed time parameters, J. Hydrol. Eng., 14, 490-498, 2009.

McDonnell, J. J. and Beven, K. J.: Debates - The future of hydrological sciences: A (common) path forward? A call to action aimed at understanding velocities, celerities, and residence time distributions of the headwater hydrograph, Water Resour. Res., 50, 5342-5350, https://doi.org/10.1002/2013WR015141, 2014.

Meyer, A. F.: The Elements of Hydrology, John Wiley and Sons, New York, 1917.

Michailidi, E. M., Antoniadi, S., Koukouvinos, A., Bacchi, B., and Efstratiadis, A.: Timing the time of concentration: shedding light on a paradox, Hydrolog. Sci. J., 63, 721-740, 2018.

Minshall, N. E.: Predicting storm runoff on small experimental watersheds, J. Hydraul. Div.-ASCE, 86, 17-38, 1960.

Morgali, J. R. and Linsley, R. K.: Computer analysis of overland flow, J. Hydraul. Div.-ASCE, 91, 81-100, 1965.

Mulvany, T. J.: On the use of self-registering rain and flood gauges in making observations of the relations of rainfall and flood discharges in a given catchment, Proc. Inst. Civ. Eng. Irel., 4, 18-33, 1851.

Musy, A. and Higy, C.: Hydrologie, Presses Polytechniques et Universitaires Romandes, Lausanne, 2004.

Nash, J. E.: Systemic determination of unit hydrograph parameters, J. Geophys. Res., 64, 111-115, 1959.

NERC: The Flood Studies Report (5 volumes), Natural Environment Research Council, Wallingford, UK, 1975.

Nowicka, B. and Soczynska, U.: Application of GIUH and dimensionless hydrograph models in ungauged basins, in: FRIENDS in Hydrology, edited by: Roald, L., Nordseth, K., and Hassel, K. A., Proc. Bolkesjø Symp., Int. Assoc. Hydrol. Sci. Publ. 187, IAHS Press, Wallingford, UK, 197-203, 1989.

O'Kelly, J. J.: The employment of unit hydrographs to determine the flows of Irish arterial drainage channels, Proc. Inst. Civ. Eng., 4, 365-445, 1955.

Overton, D. E. and Meadows, M. E.: Stormwater modelling, Academic Press, New York, 1976.

Pilgrim, D. H.: Isochrones of travel time and distribution of flood storage from a tracer study on a small watershed, Water Resour. Res., 13, 587-595, 1977.

Richards, B. D.: Flood Estimation and Control, Chapman and Hall, London, 1944.

Rodriguez-Iturbe, I.: The Geomorphological Unit Hydrograph, in: Channel Network Hydrology, edited by: Beven, K. J. and Kirkby, M. J., Wiley, Chichester, 43-68, 1993.

Rodriguez-Iturbe, I. and Valdes, J. B.: The geomorphologic structure of hydrologic response, Water Resour. Res., 15, 1409-1420, 1979.

Rodriguez-Iturbe, I., Gonzalez-Sanabria, M., and Bras, R. L.: A geomorphoclimatic theory of the instantaneous unit hydrograph, Water Resour. Res., 18, 877-886, 1982. 
Ross, C. N.: The calculation of flood discharge by the use of time contour plan isochrones, Trans. Inst. Eng. Aust., 2, 85-92, 1921.

Rosso, R.: Nash model relation to Horton order ratios, Water Resour. Res., 20, 914-920, 1984.

Sabzevari, T., Saghafian, B., Talebi, A., and Ardakanian, R.: Time of concentration of surface flow in complex hillslopes, J. Hydrol. Hydromech., 61, 269-277, 2013.

Saghafian, B. and Noroozpour, S.: Comment on "Development and testing of a new storm runoff routing approach based on time variant spatially distributed travel time method, by Jinkang Du, Hua xie, Yujun Hu, Youpeng Xu, Chong-Yu Xu, J. Hydrol., 381, 372-373, 2010.

Saghafian, B., Julian, P. Y., and Rajaie, H.: Runoff hydrograph simulation based on time variable isochrone technique, J. Hydrol., 261, 193-203, 2002.

Shaw, E. M., Beven, K. J., Chappell, N. A., and Lamb, R.: Hydrology in Practice, Spon Press, London, 2011.

Sherman, L. K.: Streamflow from rainfall by unit-graph method, Eng. News Rec., 108, 501-505, 1932.

Sherman, L. K.: Derivation of infiltration capacity $(f)$ from average loss rates $\left(f_{\mathrm{av}}\right)$, Trans. Am. Geophys. Un., 21, 541-550, 1940.

Singh, V. P.: Derivation of time of concentration, J. Hydrol., 30, 147-165, 1976.

Sklash, M. G. and Farvolden, R. N.: The role of groundwater in storm runoff, J. Hydrol., 43, 45-65, 1979.

Snyder, F. F.: Synthetic unit-graphs, Eos Trans. Am. Geophys. Union, 19, 447-454, 1938.
Turner, H. M. and Burdoin, A. S.: The flood hydrograph, J. Boston Soc. Civ. Eng., 28, 232-256, 1941.

Viessman Jr., W. and Lewis, G. L.: Introduction to Hydrology, 4th Edn., Harper Collins, New York, 1995.

WMO: International Glossary of Hydrology, WMO Report No. 385, Geneva, 1974.

Wong, T. S. W.: Comparison of celerity-based with velocity-based time of concentration of overland plane and time of travel in channels with upstream inflow, Adv. Water Resour., 26, 11711175, 2003.

Wong, T. S. W.: Evolution of kinematic wave time of concentration formulas for overland flow, J. Hydrol. Eng., 14, 739-744, 2009.

Wong, T. S. W. and Chen, C. N.: Time of concentration formula for sheet flow of varying flow regime, J. Hydrol. Eng., 2, 136-139, 1997.

Wong, T. S. W. and Laurenson, E.: Wave speed-discharge relations in natural channels, Water Resour. Res., 19, 701-706, 1983.

Young, P. C.: Hypothetico-inductive data-based mechanistic modeling of hydrological systems, Water Resour. Res., 49, 915-935, 2013.

Zoch, R. T.: On the relation between rainfall and streamflow, Mon. Weather Rev., 62, 315-322, 1934.

Zuazo, V., Gironás, J., and Niemann, J. D.: Assessing the impact of travel time formulations on the performance of spatially distributed travel time methods applied to hillslopes, J. Hydrol., 519, 1315-1327, 2014. 